\title{
SOLITARY FIBROUS TUMOR WITH INTRACRANIAL INVASION
}

\author{
Leonardo C. Welling', José Carlos Lynch', Leandro Alcy S. Ferreira', \\ Juliano Baptista Correa', Mendel Sapunaru ${ }^{3}$, Wladimir Cortezzi ${ }^{4}$, Renata Schulz ${ }^{5}$
}

Various orbital pathological process can cause unilateral proptosis, these include a variety of neoplastic and non-neoplastic lesions. The most common cause of unilateral and bilateral proptosis is Graves's disease'. Other common causes of proptosis are lymphomas and metastatic lesions. Less common causes include inflammatory pseudotumors, hemangiopericytomas, nerve sheat tumors, fibromatosis and meningeomas ${ }^{2}$. Mesenchymal tumors of the orbit account for $5-8 \%$ orbital neoplasms. These include solitary fibrous tumors (SFT) which are benign neoplasms with uncertain histogenesis ${ }^{2}$. The World Health Organization includes SFT's among mesenchymal, non-meningothelial tumors ${ }^{3}$. They have been described in the pleura ${ }^{4}, \mathrm{skin}^{5}$, orbit ${ }^{2,6}$, paranasal sinuses and other sites. Atypical or malignant SFT's are often encountered in the thorax but extrathoracic malignant tumors are much more rare ${ }^{7}$. Solitary fibrous tumors occur most commonly in adults and show a slight male predominance ${ }^{8}$.

We present an unusual case of paranasal SFT with orbital and intracranial invasion.

\section{CASE}

A 69-year-old man had a long history of sinusitis. His symptoms has initiated one year before with a slow-growing painless swelling of the left orbit. The visual field was intact and ocular movements were preserved. CT scan revealed a mass inside etmoidal sinus with destruction of its walls, invading left orbit, with destruction of its roof and with intracranial invasion (Fig 1). The patient has been operated in two stages. The intracranial mass was approached by subfrontal extradural exposure and removed with microsurgical techniques. A irregular defect in the anterior skull base was observed. The proximity to vital structures and the limited visual field lead us to stop the surgery after the total removal of the intracranial mass and scheduled the second stage for later on. The second stage was performed through
"Le Fort III" osteotomy with a complete resection of etmoidal and orbital portion of tumor (Fig 2). An excellent recovery was observed and his proptosis resolved in one month. The histopathology revealed large collagenized areas, thick and hyalinizedwalled vessels immunohistochemical testing resulted in proeminent staining for CD-34 (Fig 3).

\section{DISCUSSION}

The solitary fibrous tumor was first described as a primary spindle-cell tumor of the pleura in $1931^{\circ}$. Initially, it was thought that SFT was mesothelial in origin. However, electron microscopic and immunophenotypic investigations have shown that the SFT is myofibroblastic in nature ${ }^{10}$.

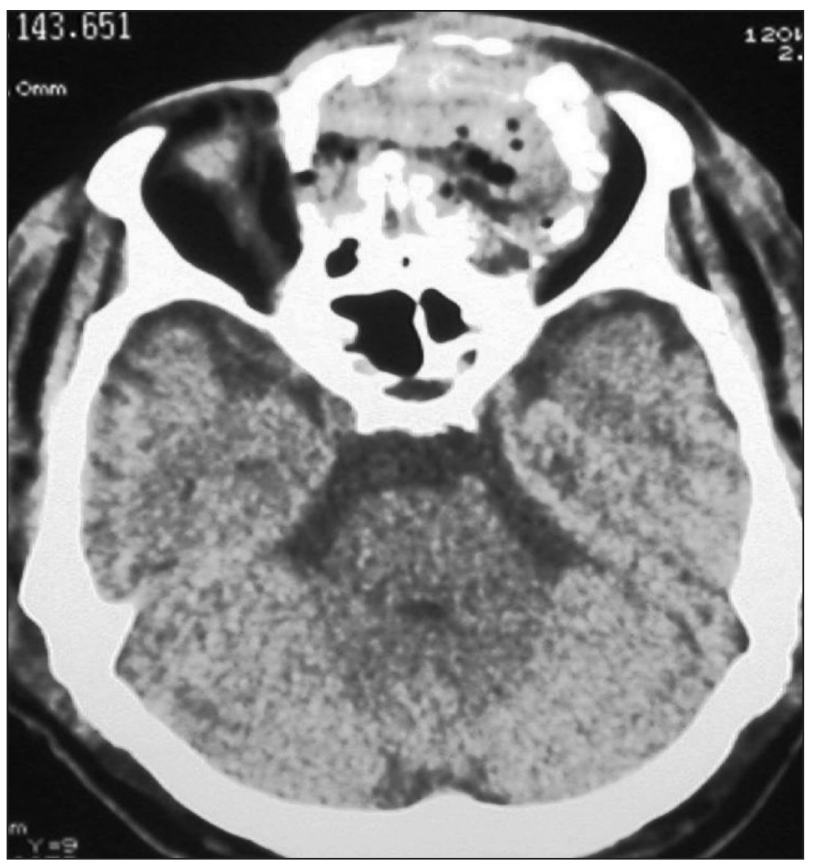

Fig 1. CT scan shows the etmoidal part of the tumor.

\section{TUMOR SOLITARIO FIBROSO COM INVASÃO INTERCRANIANA}

Serviço de Neurocirurgia do Hospital Servidores do Estado do Rio de Janeiro, Brazil (HSE - RJ); 'Residente do Serviço de Neurocirurgia do HSE - RJ; ${ }^{2}$ Chefe do Serviço de Neurocirugia do HSE - RJ; ${ }^{3}$ Neurocirurgião do HSE - RJ; ${ }^{4}$ Chefe do Serviço de Cirurgia Buco-Maxilo-Facial do HSE - RJ; ${ }^{5}$ Residente do Serviço de Patologia.

Received 26 January 2009, received in final form 4 May 2009. Accepted 11 May 2009.

Dr. Leonardo C. Welling - Rua Sacadura Cabral 178 - Hospital dos Servidores do Estado RJ / Serviço de Neurocirurgia / $7^{\circ}$ andar - $20221-161$ Rio de Janeiro RJ - Brasil. E-mail: leonardowelling@yahoo.com.br 


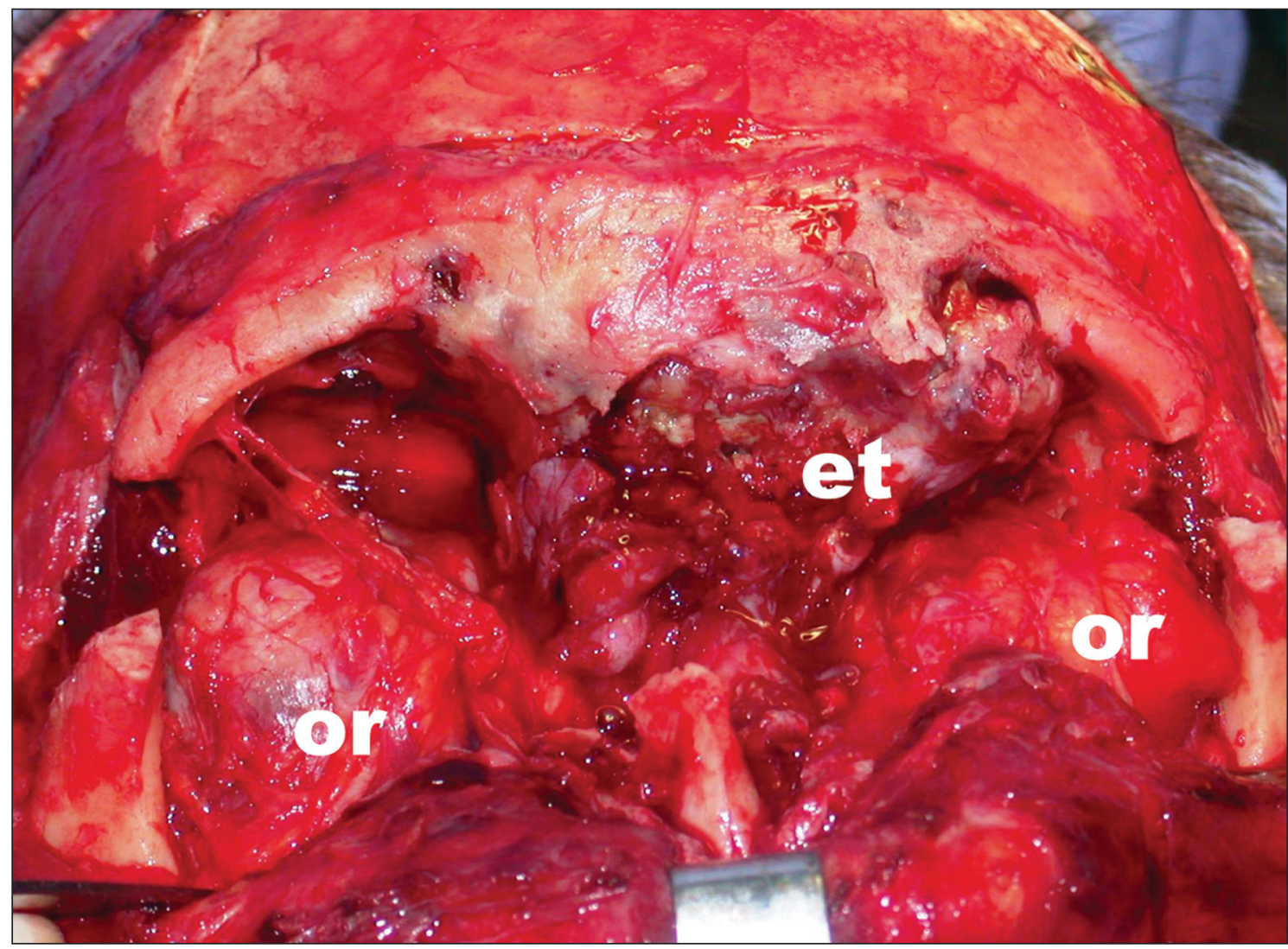

Fig 2. Le Fort III osteotomy. Etmoidal part of tumor (et), Orbit (or).

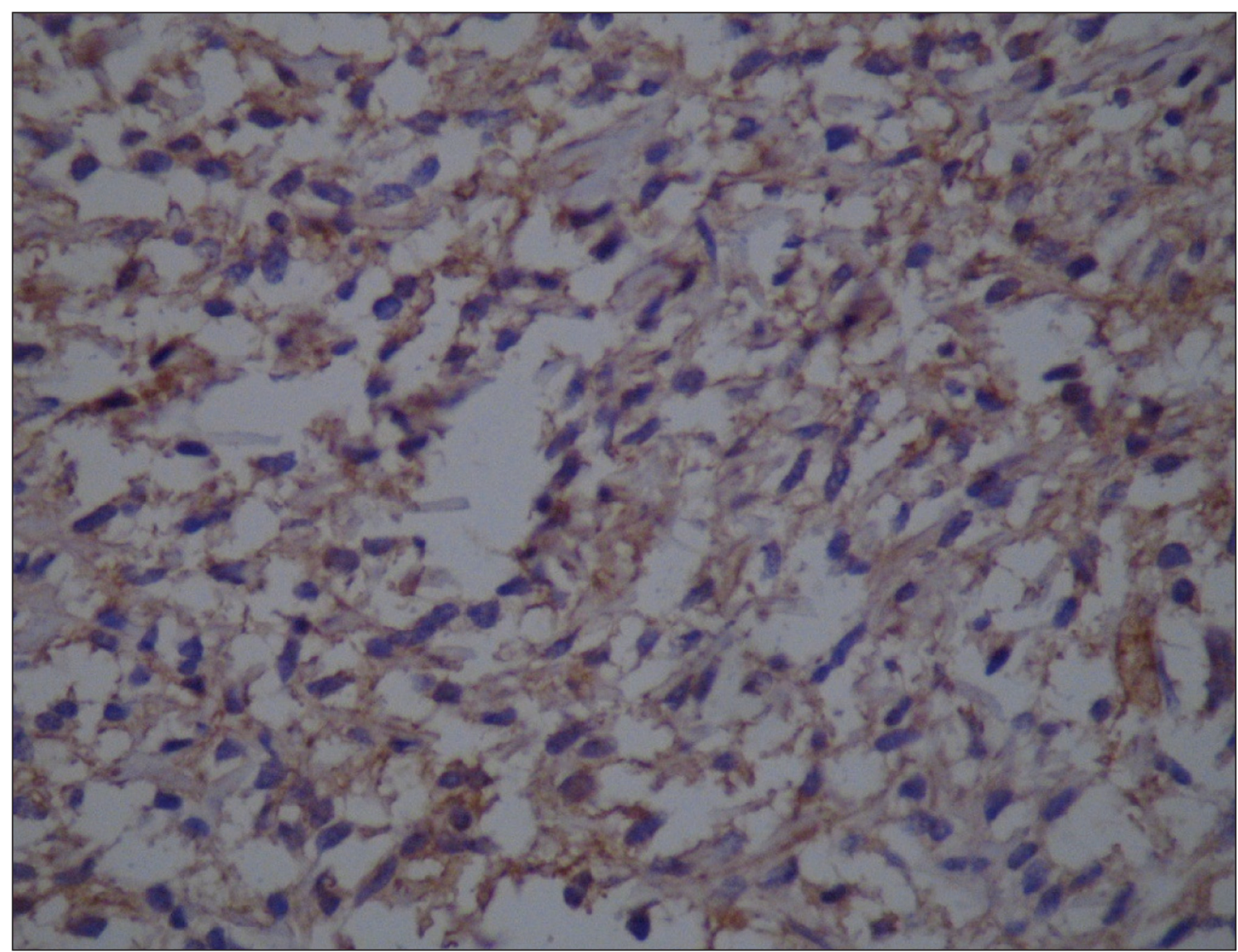

Fig 3. Immunohistochemical testing with proeminent staining for CD-34. 
Nasal SFT's typically lead to nasal obstruction and also may be associated with epistaxis, rhinorrhea, anosmia, headache, facial pain and visual disturbances caused by orbital pressure. ${ }^{7}$. As SFTs in most sites, the definitive treatment of solitary fibrous tumor is the complete tumor excision. Partially resected tumors have been noted to persist for years and recur ${ }^{6}$.

The majority of head and neck SFTs seem to be a benign and recurrence or metastasis rarely have been documented. Large tumor size and necrosis are also poor prognostic factors. In most reported cases the tumor cells stained positive for vimentin and CD34, and not by S-100 protein". CD 34 has in recent years been shown to be strongly and diffusely expressed in SFT's. CD 34 is not entirely specific for SFT and expresses in a variety of spindle cell neoplasms, such as dermatofibrosarcoma protuberans or neurofibromas ${ }^{8}$.

The most difficult distinction often is with hemangiopericytoma (HPC), which some authors consider to be a closely related tumor. While there is considerable overlap in the histologic features of these two tumors, HPC shows more diffuse vascularity with more proeminent staghorn vessels. In addition, CD 34 staining is more often focal and weak in HPC whereas it is usually strong and diffuse in $\mathrm{SFT}^{12}$.

Multiple chromosomal abnormalities, including translocations and gains of chromosomes have been reported. Further cytogenetic studies need to be carried out to identify specific chromosomal alterations to understand the biology of this tumor ${ }^{13}$.

In conclusion, the SFT is a benign neoplasm with uncertain histogenesis that rarely occurs in the head and neck region but it should be considered in the differential diagnosis of spindle cell lesions arising in the paranasal sinus, orbit, and invading intracranial structures.
The definitive treatment is the complete tumor excision since partially resected lesions have been noted to persist for years and recur.

\section{REFERENCES}

1. Saha S, Saha VP, Chattopadhyay S. Orbital and paraorbital tumors: clinicopathological profile and surgical management. Indian J Otolaryngol Head Neck Surg 2002;54:117-122.

2. Dorfman MD, King T, Dickersen GR, Rosenberg AE, Pilch BZ. Solitary fibrous tumor of the orbit. Am J Surg Pathol 1994;18:281-287.

3. Pakasa NM, Pasavier B, Chambonniere ML, et al. Atypical presentations of solitary fibrous tumors of the central nervous system: an analysis of unusual clinicopathological and outcome patterns in three new cases with a review of the literature. Virchows Arch 2005;447:81-86.

4. De Perrot M, Fischer S, Brundler MA, Sekine Y, Keshavjee S. Solitary fibrous tumors of the pleura. Ann Thorac Surg 2002;74:285-293.

5. Cowper SE, Kilpatrick T, Proper S, Morgan MB. Solitary fibrous tumor of the skin. Am J Dermatopathol 1999;21:213-219.

6. Polito F, Tosi M, Tosi P, Schurfeld K, Caporossi A. Orbital solitary fibrous tumor with aggressive behavior: three cases and review of the literature. Graefes Arch Clin Exp Ophthalmol 2002;240:570-574.

7. Hicks DL, Moe KS. Nasal solitary fibrous tumor arising from the anterior cranial fossa. Skull Base 2004;14:203-207.

8. Nikas DC, De Girolami U, Folkerth RD, Bello L, Zamani AA, Black PMcL. Parasagittal solitary fibrous tumor of the meninges: case report and review of the literature. Acta Neurochir (Wien) 1999;141:307-313.

9. Klemperer P, Rabin CB. Primary neoplasms of the pleura: a report of five cases. Arch Pathol 1931;11:385-412.

10. Cassarino DS, Auerbach A, Rushing EJ. Widely invasive solitary fibrous tumor of the sphenuid sinus, cavernous sinus and pitutary fossa Ann Diag Pathol 2003;7:169-173.

11. Alawi F, Stratton D, Freedman PD. Solitary fibrous tumor of the oral soft tissues: a clinicopathologic and immunohistochemical study of 16 cases. Am J Surg Pathol 2001;25:900-910.

12. Perry A, Scheithauer BW, Nascimento AG. The immunophenotypic spectrum of meningeal hemangiopericytoma: a comparison with fibrous meningeoma and solitary fibrous tumor of meninges. Am J Surg Path 1997;21:1354-1360.

13. Cerdá-Nicolas M, Lopes-limes C, Eil-Bensor, et al. Solitary fibrous tumor of the orbit: morphological, cytogenetic and molecular features. Case report. Neuropathology 2006;26:557-563. 